\title{
Heat Resistant Properties of Some Elements-Incorporated Diamond-Like Carbon Films and Their Trial Applications for Micro End Mill Coatings
}

\author{
Chavin Jongwannasiri ${ }^{*}$, Nutthanun Moolsradoo' ${ }^{2}$, Shuichi Watanabe ${ }^{3}$ \\ ${ }^{1}$ Systems Engineering Major, Graduate School, Nippon Institute of Technology, Saitama, Japan \\ ${ }^{2}$ Production Technology Education Department, King Mongkut's University of Technology Thonburi, Bangkok, \\ Thailand \\ ${ }^{3}$ Department of Innovative Systems Engineering, Nippon Institute of Technology, Saitama, Japan \\ Email: ${ }^{*}$ chavin.jon@outlook.co.th
}

Received 26 October 2014; revised 25 November 2014; accepted 10 December 2014

Copyright $@ 2015$ by authors and Scientific Research Publishing Inc.

This work is licensed under the Creative Commons Attribution International License (CC BY).

http://creativecommons.org/licenses/by/4.0/

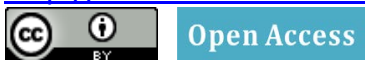

\begin{abstract}
In this article, the results obtained from a study carried out on the some elements-incorporated diamond-like carbon (DLC) films are reported. All the films were deposited using plasma-based ion implantation (PBII) technique. The deposited films were annealed at $400^{\circ} \mathrm{C}, 650^{\circ} \mathrm{C}$ and $900^{\circ} \mathrm{C}$ in an air atmosphere for 1 hour. The effects of adding hydrogen, silicon/oxygen and silicon/nitrogen into the DLC film on chemical composition, friction coefficient and corrosion resistance were investigated. The films coated micro end mills performance was also assessed. The results indicate that all the films showed almost constant atomic contents of $\mathrm{C}, \mathrm{Si}, \mathrm{O}$ and $\mathrm{N}$ until annealing at $400^{\circ} \mathrm{C}$. However, the films were completely destroyed at $650^{\circ} \mathrm{C}$ with the increased $S i$ and 0 contents, while the $C$ content decreased. The incorporation of silicon/oxygen and silicon/nitrogen into the DLC exhibited lower values of friction coefficients than the hydrogenated DLC (DLC and H-DLC) before and after annealing at $400^{\circ} \mathrm{C}$, whereas all the films presented the same values of friction coefficients after annealing at $650^{\circ} \mathrm{C}$ due to the completely destroy of the films. Furthermore, the incorporation of silicon/nitrogen into the DLC also exhibited better corrosion resistance and unbroken micro end mills performance on their surfaces. Thus, the incorporation of silicon/nitrogen into the DLC film can be considered beneficial in improving the micro end mills performance.
\end{abstract}

\footnotetext{
${ }^{*}$ Corresponding author.
} 
Keywords

Cutting Tools, Diamond-Like Carbon, Micro End Mills

\section{Introduction}

Micro-manufacturing is a rapidly growing worldwide industry calculated at $\$ 60$ billion [1]. This rapid growth is largely due to the increased interest in fabricating micro/meso-scaled components that will expand the microand nano-scaled worlds to the macroworld [2]. One of growing importance in micro-manufacturing process is micro end milling. Owing to the direct scale-down of macroscopic end milling, micro end milling is a material removal process that can create high aspect ratio, three-dimensional features in a single step [2]-[4]. It is not only limited use in special clean room environments, but also compatible with various engineering materials such as polymers [5], metals and metal alloys [5]-[8], and pre-sintered powder ceramics [9] [10]. There are many important challenges to overcome when scaling down end mills to microscopic sizes. For instance, micro tools have low flexural stiffness and strength due to their small diameter, which are easily damaged, resulting in rapid tool degradation [3] [4] [7]. Also, any chips adhering to the tool will eliminate a path for chips to void the cutting zone and will result in a spike in the cutting forces, leading to terrible tool fracture due to the low flexural strength of the tool.

Diamond-like carbon (DLC) is a metastable amorphous film that exhibits unique properties such as chemical inertness, high hardness, low friction coefficient, and high wear and corrosion resistance. Thus, these films are commonly applied in the protective coatings of cutting tools, magnetic storage disks and biomedical applications [11]-[13]. However, a number of limitations exist regarding the use of DLC. Depending on the environment, the films can exhibit a poor friction coefficient and limited corrosion resistance, as well as low adhesion between the film and substrate due to high intrinsic compressive stress. Many researchers have reported that the introduction of additional elements, such as silicon, oxygen, nitrogen and various metals, improves the properties of DLC [11]. The methods used to create DLC films include ion beam assisted deposition (IBAD), magnetron sputtering deposition (MSD), chemical vapor deposition (CVD) and plasma-based ion implantation (PBII) [14]-[17]. Among these methods, the PBII process is considered one of the most promising techniques owing to its ability to uniformly implant and deposit ions into three-dimensional substrates with complex shapes. In this article, PBII was utilized to prepare three different elements including hydrogen, silicon/oxygen and silicon/nitrogenincorporated DLC films (henceforth denoted as H-DLC, Si-O-DLC and Si-N-DLC, respectively). The aim of this study was to investigate the effects of added-elements on the film properties and micro end mills performance after the deposition of DLC films.

\section{Experimental Details}

A schematic of the PBII system used for the deposition of the DLC, H-DLC, Si-O-DLC and Si-N-DLC films was previously described in the literature [18]. Si (100) wafers measuring $0.7 \mathrm{~mm}$ in thickness and Tungsten carbide (WC) end mills (Union Tool Company, Japan) with an approximate cutting edge radius of $1 \mathrm{~mm}$ were used as substrates. The wafers and end mills were sputter-cleaned with $\mathrm{Ar}^{+}$for $20 \mathrm{~min}$ to remove residual surface contaminants and surface oxides using a negative-pulsed bias voltage of $10 \mathrm{kV}$. Using a negative-pulsed bias voltage of $20 \mathrm{kV}$, the DLC film interlayer was first deposited with $\mathrm{CH}_{4}$ for $60 \mathrm{~min}$ to improve adhesion between the film and the substrate. The DLC, H-DLC, Si-O-DLC and Si-N-DLC films were deposited at a negativepulsed bias voltage of $5 \mathrm{kV}$, and the total thickness of the films was approximately $500 \mathrm{~nm}$. The gaseous mixtures ratio of H-DLC $\left(\mathrm{C}_{2} \mathrm{H}_{2}: \mathrm{H}_{2}\right)$, Si-O-DLC $\left(\mathrm{C}_{2} \mathrm{H}_{2}: \mathrm{TMS}: \mathrm{O}_{2}\right)$ and Si-N-DLC $\left(\mathrm{C}_{2} \mathrm{H}_{2}: \mathrm{TMS}: \mathrm{N}_{2}\right)$ films were 2:1, 14:1:2 and 14:1:2, respectively. The deposition pressure was also set to $2 \mathrm{~Pa}$.

The films were used to investigate various annealing temperatures. The deposited films were annealed (held at the following temperature) at $400^{\circ} \mathrm{C}, 650^{\circ} \mathrm{C}$ and $900^{\circ} \mathrm{C}$ in an air atmosphere for 1 hour. The properties of the films were studied using several characterization techniques. The composition at the top surface of the films was measured using energy dispersive X-ray spectroscopy (EDS). The friction coefficient of the films was assessed using ball-on-disk friction testing (CSEM; Tribotester). A dry sliding test was performed using a ball indenter, AISI440C (SUS440C, diameter of $6.0 \mathrm{~mm}$ ) under a normal applied load of $3 \mathrm{~N}$, a rotation radius of $3 \mathrm{~mm}$, a 
linear speed of $31.4 \mathrm{~mm} / \mathrm{s}$, and 10,000 frictional rotations. The tests were performed under ambient air at room temperature. The electrochemical behavior was measured with a standard three-electrode electrochemical cell. $\mathrm{An} \mathrm{Ag} / \mathrm{AgCl}$ was used as the reference electrode with a platinum counter electrode. The potentio dynamic experiment was conducted using a computer-controlled potentio stat (AUTOLAB). The specimen was immersed in the $0.05 \mathrm{M} \mathrm{NaCl}$ solution under ambient air. After the specimen had been immersed in the experimental solution for 30 min under open-circuit conditions, polarization experiments were conducted. The micro end mills performance was conducted by machining on a 2205 duplex stainless steel workpieces measuring $2.0 \mathrm{~mm}$ in thickness. All machining was done at $6000 \mathrm{rpm}$ spindle speed, $150 \mathrm{~mm} / \mathrm{min}$ feedrate without the application of any lubricant (dry condition) for 300 holes. For each condition, three pieces of micro end mill were measured. After the machining, diameter of micro end mills was evaluated using optical microscope.

\section{Results and Discussion}

The carbon, silicon, oxygen and nitrogen concentrations measured at the top surface were measured using EDS, and values are always given in units of atomic percentage (at.\%). Because hydrogen content cannot be measured using EDS, concentrations are normalized to a total of 100 at.\%, neglecting the hydrogen contribution. Figures 1(a)-(d) shows the percentage of the relative atomic contents before and after annealing in air at the top surface of DLC, H-DLC, Si-O-DLC and Si-N-DLC films, respectively. All the films presented almost constant atomic contents of $\mathrm{C}, \mathrm{Si}, \mathrm{O}$ and $\mathrm{N}$ until annealing at $400^{\circ} \mathrm{C}$. However, the $\mathrm{C}$ content in the films rapidly decreased, while the Si and $\mathrm{O}$ contents increased at annealing temperatures over $400^{\circ} \mathrm{C}$, and the films were completely destroyed at $650^{\circ} \mathrm{C}$. This result is consistent with the finding of Yang et al. that pure DLC films were completely destroyed over $500^{\circ} \mathrm{C}$, whereas diamond-like characteristics of the Si-O-DLC films were disappeared when

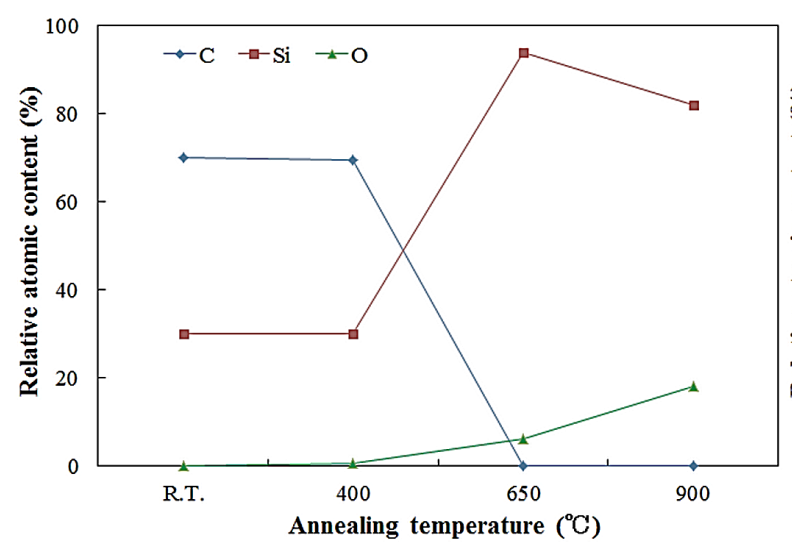

(a)

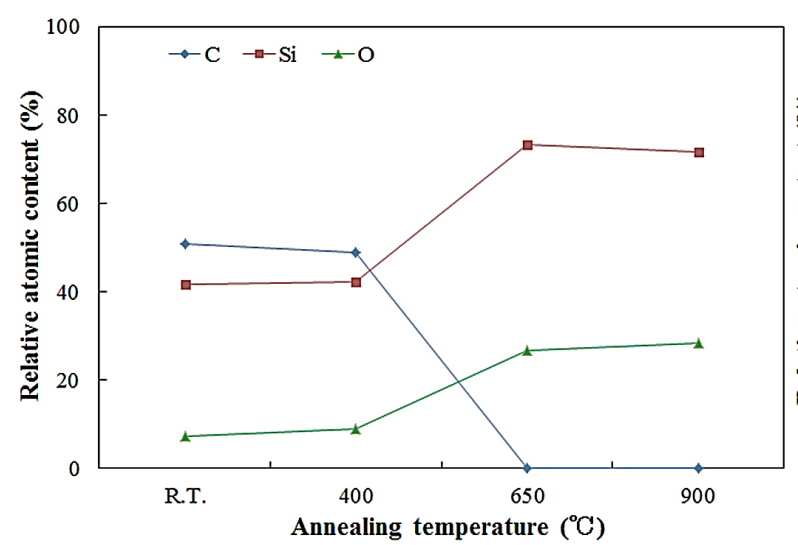

(c)

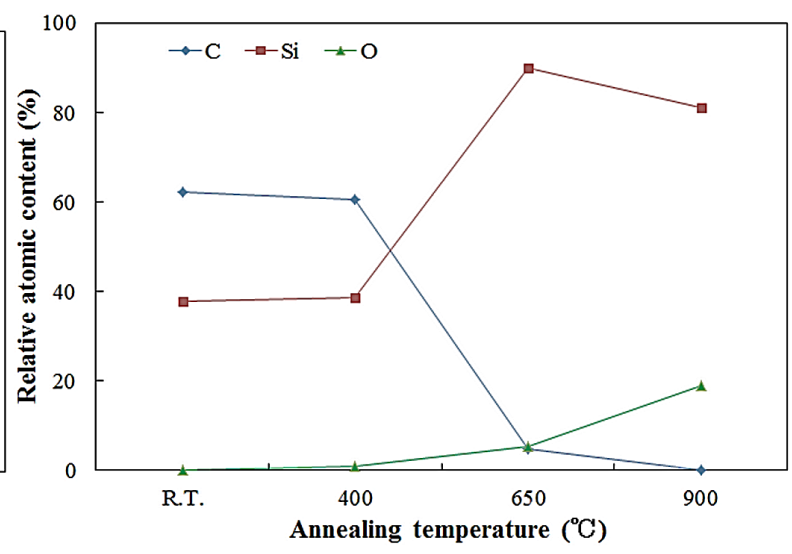

(b)

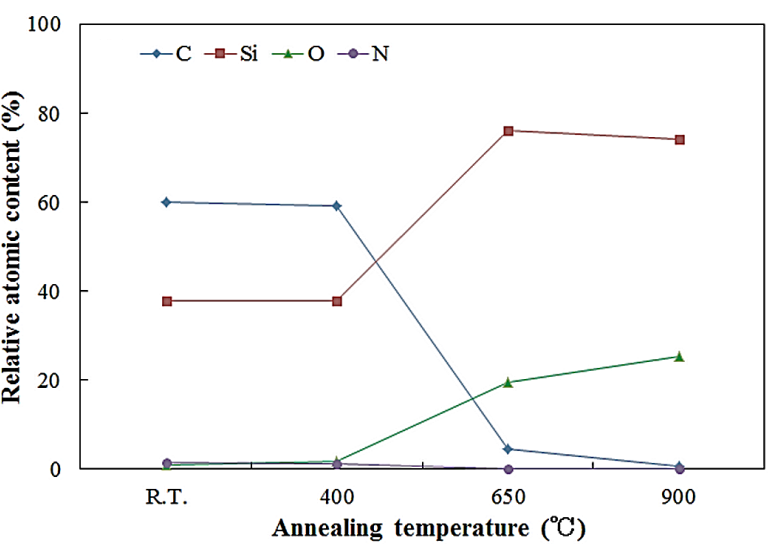

(d)

Figure 1. Percentage of the relative atomic contents of (a) DLC, (b) H-DLC, (c) Si-O-DLC and (d) Si-N-DLC films annealed in air at various temperatures. 
heated to $600^{\circ} \mathrm{C}$ [19]. Furthermore, the H-DLC and Si-N-DLC films have the same results with the pure DLC and Si-O-DLC films. These results imply that oxygen from the air reacted with the film during the thermal annealing, and the given temperature resulted in a structural transition of the films. Consequently, the results indicate that the $\mathrm{Si}$ and $\mathrm{O}$ contents increased with increasing annealing temperature, and thus the relative atomic content of carbon decreased.

The friction coefficients of H-DLC, Si-O-DLC and Si-N-DLC compared to DLC films measured under ambient air are shown in Figure 2(a). The influence of the hydrogen, silicon, oxygen and nitrogen contents on the friction coefficients of the H-DLC, Si-O-DLC and Si-N-DLC films was examined. As shown in Figure 2(a), all the films had stable, lower values of friction coefficients and longer friction endurance within the range of 0.04 0.16. However, it is quite obvious that the friction coefficient of the DLC was higher than that of the elementsincorporated DLC films. The H-DLC film had a value of friction coefficient of approximately 0.13 , whereas the Si-O-DLC and Si-N-DLC films had lower values of friction coefficients of approximately 0.06 and 0.04 , respectively. In the case of the Si-O-DLC film, the result indicates a low friction coefficient, which is related to the formation of silicon-rich oxide debris and the transfer of silicon oxide layers on the steel ball surfaces [20]. This silicon oxide layer prevents direct contact between the film and ball when sliding, resulting in the low friction forces. Additionally, in the case of the Si-N-DLC film, the result indicates a low friction coefficient due to the incorporation of silicon and nitrogen [21]. However, the nitrogen content may be less influential than the silicon content, which was described in the literature [22]. These results indicate that the friction coefficient of the DLC films is affected by the incorporation of hydrogen, silicon/oxygen and silicon/nitrogen.

The friction coefficients of the films after annealing in air at $400^{\circ} \mathrm{C}$ and $650^{\circ} \mathrm{C}$ are shown in Figures 2(b), Figures 2(c). The results indicate that all the films had higher values of friction coefficients of approximately 0.8 because the diamond-like characteristics disappeared and the films were completely destroyed when heated

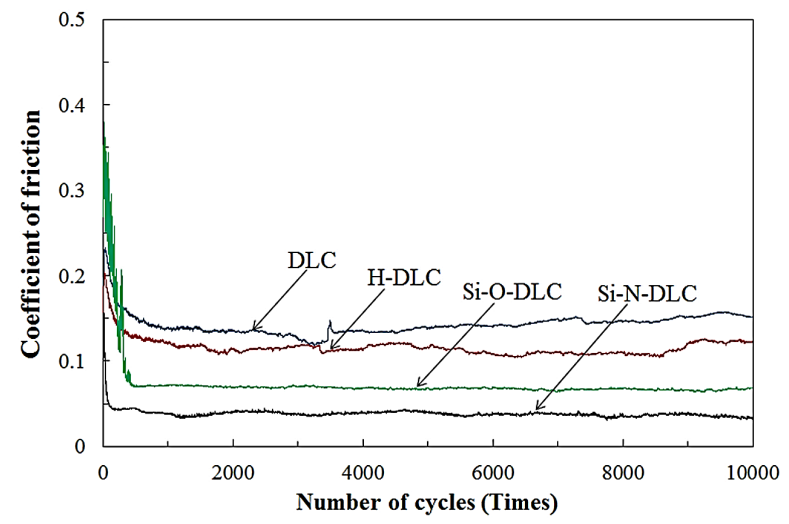

(a)

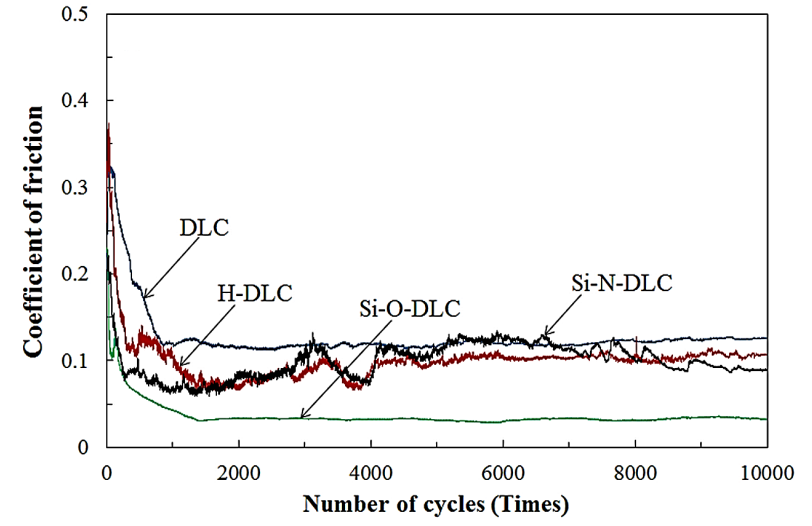

(b)

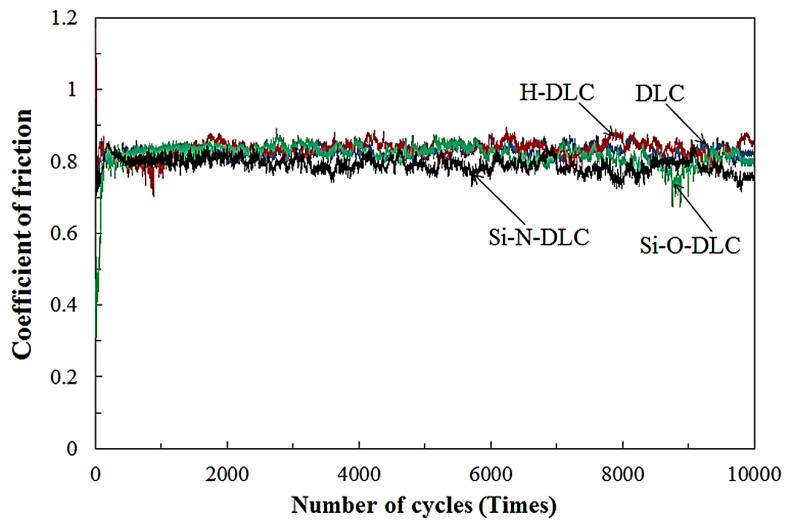

(c)

Figure 2. Friction coefficients of the H-DLC, Si-O-DLC and Si-N-DLC compared to DLC films measured (a) under ambient air, (b) after annealing at $400^{\circ} \mathrm{C}$ and (c) after annealing at $650^{\circ} \mathrm{C}$. 
to $650^{\circ} \mathrm{C}$, which was confirmed by the percentage of the relative atomic contents, as shown in Figure 1. In contrast, all the films annealed at $400^{\circ} \mathrm{C}$ still had lower values of friction coefficients, especially the Si-O-DLC film. This is due to the reaction between the Si-O-DLC film and oxygen in the oven, inducing the formation of silicon oxide layers on the film surface and enhancing a low value of friction coefficient of approximately 0.04 . Consequently, it is assumed that the incorporation of hydrogen, silicon/oxygen and silicon/nitrogen into DLC films yields the low friction coefficients for protective coating applications when heated up to $400^{\circ} \mathrm{C}$.

The potentiodynamic polarization curves of H-DLC, Si-O-DLC and Si-N-DLC compared to DLC films in $0.05 \mathrm{M} \mathrm{NaCl}$ solution are shown in Figure 3. In general, the samples with a lower current density and a higher potential indicate better corrosion resistance. It can be clearly observed from a shift of the whole polarization curve towards the region of lower current density and higher potential that the incorporation of silicon/nitrogen into the DLC significantly improves the corrosion resistance. For the Si-N-DLC film, the polarization curve moves to the region of higher potential and lower current density, while the other films exhibit a few lower or higher potential compared to the DLC film. The enhancement in the corrosion resistance of the Si-N-DLC film may be attributed to the reduced electrical conductivity. The low electrical conductivity of the Si-N-DLC film reduces the electron transport and the electrical charge exchange at the surface, which are the cause of the electrochemical corrosion [23]. Additionally, the H-DLC and Si-O-DLC films presented their higher and lower values of potentials, indicating better and worse corrosion resistance than the DLC, respectively. Based on these results, the incorporation of silicon/nitrogen into the DLC film can act as a passive barrier to prevent aggressive ions in the corrosion solution from attacking the substrate.

Finally, the performance of DLC, H-DLC, Si-O-DLC and Si-N-DLC coated micro end mills was investigated. Figure 4 shows the diameter of coated micro end mills before and after machining on the workpieces. As shown in Figure 4, the H-DLC and Si-N-DLC coated micro end mills had larger diameter after machining on the workpieces. This is due to the adhesion of debris from workpiece on the micro end mills during the machining. Furthermore, the heating occurred during the machining also can fuse the debris to the micro end mills, inducing larger diameter on the workpieces. In contrast, the Si-O-DLC coated micro end mill had a smaller diameter after machining on the workpiece due to lower hardness of the film (approximately $10.0 \mathrm{GPa}$ ), indicating deterioration of the film during the machining. These data are consistent with the diameter of hole measured at the sequence of $1^{\text {st }}$ and $300^{\text {th }}$, as shown in Figure 5. Additionally, the DLC coated micro end mill had broken during the machining, at the quantity of 200 holes, due to higher friction coefficient of the film, which induced the shear force occurred in the micro end mills. The uncoated micro end mill had also broken during the machining, at the quantity of 120 holes, due to the shear force occurred in the micro end mill. Based on these results, the incorporation of hydrogen and silicon/nitrogen into the DLC film can improve the micro end mills performance.

\section{Conclusion}

All the films were successfully prepared on Si (100) wafers and micro end mills using the PBII technique. The films were investigated for the effects of adding hydrogen, silicon/oxygen and silicon/nitrogen into the DLC

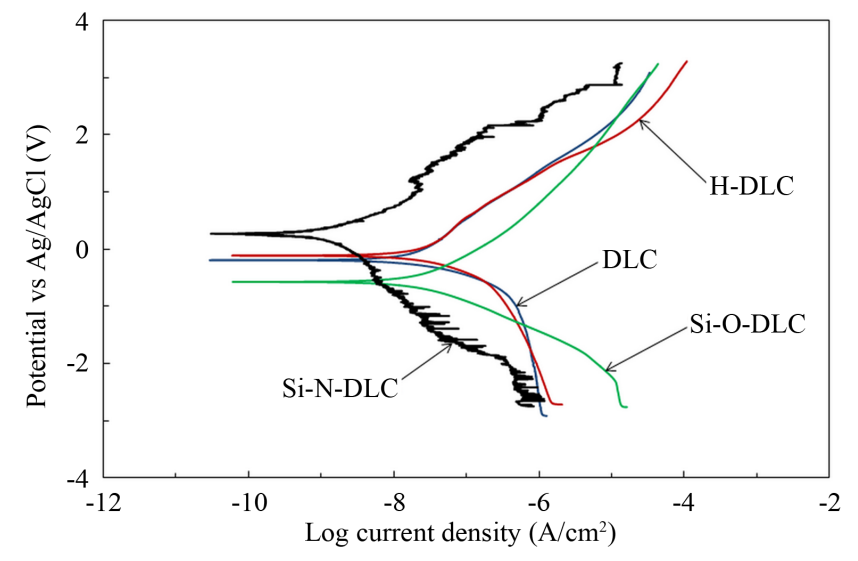

Figure 3. Potentiodynamic polarization curves of the H-DLC, Si-ODLC and Si-N-DLC compared to DLC films. 


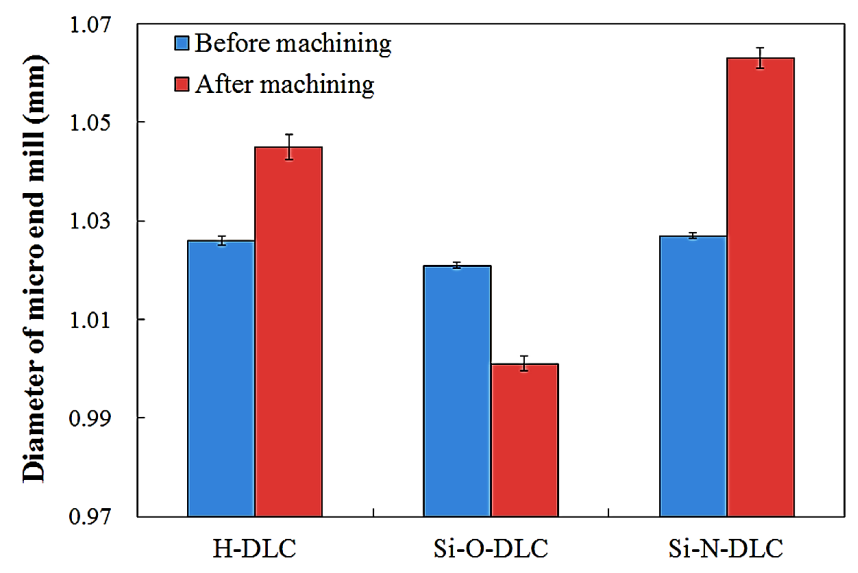

Figure 4. Diameter of the H-DLC, Si-O-DLC and Si-N-DLC coated micro end mills before and after machining for 300 holes.

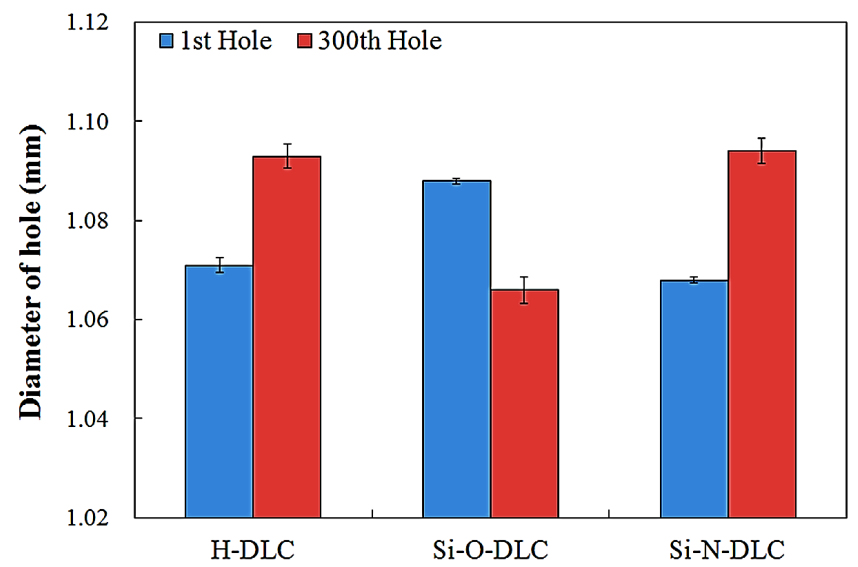

Figure 5. Diameter of hole after machining on a 2205 duplex stainless steel workpieces at the sequence of $1^{\mathrm{st}}$ and $300^{\text {th }}$.

film on chemical composition, friction coefficient and corrosion resistance. The films coated micro end mills performance was also assessed. All the films showed almost constant atomic contents of $\mathrm{C}, \mathrm{Si}, \mathrm{O}$ and $\mathrm{N}$ until annealing at $400^{\circ} \mathrm{C}$; however, the films were completely destroyed at $650^{\circ} \mathrm{C}$. The Si-O-DLC and Si-N-DLC films exhibited lower values of friction coefficients than the DLC and H-DLC films before and after annealing at $400^{\circ} \mathrm{C}$. On the other hand, all the films had the same values of friction coefficients after annealing at $650^{\circ} \mathrm{C}$. Furthermore, the Si-N-DLC film also exhibited better corrosion resistance and unbroken micro end mills performance on their surfaces. Due to aforementioned reasons, it can be concluded that the Si-N-DLC film can be considered beneficial for applying to improve the micro end mills performance.

\section{Acknowledgements}

This work was financially supported by the National Research Council of Thailand (2557A30602294 and 2558A30602191).

\section{References}

[1] Bruno, F., Friedrich, C. and Warrington, R.O. (1995) The Miniturization Technologies: Past, Present, and Future. IEEE Transactions on Industrial Electronics, 42, 423-430. http://dx.doi.org/10.1109/41.464603

[2] Williams, R.E., Huang, Y., Melkote, S., Kinsey, B., Sun, W. and Yao, D. (2005) Recent Advances in Micro/MesoScale Manufacturing Processes. ASME 2005 International Mechanical Engineering Congress and Exposition, Orlando, 5-11 November 2005, ICMECE2005-79889. 
[3] Liu, X., Devor, R.E., Kapoor, S.G. and Ehmann, K.F. (2004) The Mechanics of Machining at The Microscale: Assessment of The Current State of The Science. ASME Journal of Manufacturing Science and Engineering, 126, 666-678. http://dx.doi.org/10.1115/1.1813469

[4] Kobayashi, A. (2005) The Features and Application of UPC Nano-Micro Forming Tools. Industrial Diamond Review, 65, 28-30.

[5] Damazo, B.N., Davies, M.A., Dutterer, B.S. and Kennedy, M.D. (1999) A Summary of Micro-milling Studies. First International Conference and General Meeting of the European Society of Precision Engineering and Nanotechnology, Bremen, 30 May-4 June 1999, 322-325.

[6] Friedrich, C., Coane, P., Goettert, J. and Gopinathin, N. (1998) Direct Fabrication of Deep X-Ray Lithography Masks by Micromechanical Milling. Precision Engineering, 22, 164-173. http://dx.doi.org/10.1016/S0141-6359(98)00012-9

[7] Kim, C.-J., Bono, M. and Ni, J. (2002) Experimental Analysis of Chip Formation in Micro-Milling. Technical Paper Society of Manufacturing Engineers, MR02-159.

[8] Jackson, M.J., Robinson, G.M. and Ahmed, W. (2006) Micromachining Selected Metals Using Diamond Coated Cutting Tools. International Journal of Nanomanufacturing, 1, 304-317. http://dx.doi.org/10.1504/IJNM.2006.012201

[9] Isomura, K., Murayama, M., Yamaguchi, H., Ijichi, N., Saji, N., Shiga, O., Takahashi, K., Tanaka, S., Genda, T. and Esashi, M. (2003) Development of Micro-Turbo Charger and Micro-Combustor as Feasibility Studies of Three-Dimensional Gas Turbine at Micro-Scale. ASME Turbo Expo 2003, Collocated with the 2003 International Joint Power Generation Conference, Atlanta, 16-19 June 2003, 685-690. http://dx.doi.org/10.1115/GT2003-38151

[10] Jeon, Y. and Pfefferkorn, F.E. (2007) Laser-Assisted Machining of Silicon Nitride with Cubic Boron Nitride Tipped Micro End Mill. Second International Conference on Micro-Manufacturing, South Carolina, 43.

[11] Robertson, J. (2002) Diamond-Like Amorphous Carbon. Materials Science and Engineering Reports, 37, $129-281$. http://dx.doi.org/10.1016/S0927-796X(02)00005-0

[12] Cho, S.-J., Chung, J.-W. and Lee, K.-R. (2005) Characterization of the Mechanical Properties of Diamond-Like Carbon Films. Diamond and Related Materials, 14, 1270-1276. http://dx.doi.org/10.1016/j.diamond.2004.11.034

[13] Singh, R.A., Yoon, E.-S., Kim, H.J., Kong, H., Park, S.-J. and Lee, K.-R. (2006) Friction Behaviour of Diamond-Like Carbon Films with Varying Mechanical Properties. Surface and Coatings Technology, 201, 4348-4351. http://dx.doi.org/10.1016/j.surfcoat.2006.08.055

[14] Cotell, C.M. and Hirvonen, J.K. (1996) Effect of Ion Energy on The Mechanical Properties of Ion Beam Assisted Deposition (IBAD) Wear Resistant Coatings. Surface and Coatings Technology, 81, 118-125. http://dx.doi.org/10.1016/0257-8972(95)02650-9

[15] Noshiro, J., Watanabe, S., Sakurai, T. and Miyake, S. (2006) Friction Properties of Co-Sputtered Sulfide/DLC Solid Lubricating Films. Surface and Coatings Technology, 200, 5849-5854. http://dx.doi.org/10.1016/j.surfcoat.2005.08.147

[16] Ikeyama, M., Miyagawa, S., Miyagawa, Y., Hayakawa, Y. and Miyajima, T. (2007) DLC Coatings on Inner Walls of PET Bottles by a Simplified PBII Technique. Surface and Coatings Technology, 201, 8112-8115. http://dx.doi.org/10.1016/j.surfcoat.2006.02.064

[17] Günther, M., Bialuch, I., Peter, S., Bewilogua, K. and Richter, F. (2011) High Rate Deposition of Hard a-C:H Films Using Microwave Excited Plasma Enhanced CVD. Surface and Coatings Technology, 205, S94-S98. http://dx.doi.org/10.1016/j.surfcoat.2010.12.047

[18] Jongwannasiri, C., Moolsradoo, N., Khantachawana, A., Kaewtatip, P. and Watanabe, S. (2012) The Comparison of Biocompatibility Properties between Ti Alloys and Fluorinated Diamond-Like Carbon Films. Advances in Materials Science and Engineering, 2012, 1-8. http://dx.doi.org/10.1155/2012/724126

[19] Yang, W.J., Choa, Y.-H., Sekino, T., Shim, K.B., Niihara, K. and Auh, K.H. (2003) Thermal Stability Evaluation of Diamond-Like Nanocomposite Coatings. Thin Solid Films, 434, 49-54. http://dx.doi.org/10.1016/S0040-6090(03)00466-8

[20] Yang, S.H., Kong, H., Lee, K.-R., Park, S. and Kim, D.E. (2002) Effect of Environment on the Tribological Behavior of Si Incorporated Diamond-Like Carbon Films. Wear, 252, 70-79. http://dx.doi.org/10.1016/S0043-1648(01)00856-0

[21] Saha, B., Liu, E., Tor, S.B., Khun, N.W., Hardt, D.E. and Chun, J.H. (2010) Replication Performance of Si-NDLC-Coated Si Micro-Molds in Micro-Hot-Embossing. Journal of Micromechanics and Microengineering, 20, 1-8. http://dx.doi.org/10.1088/0960-1317/20/4/045007

[22] Jongwannasiri, C., Li, X. and Watanabe, S. (2013) Improvement of Thermal Stability and Tribological Performance of Diamond-Like Carbon Composite Thin Films. Materials Sciences and Applications, 4, 630-636. http://dx.doi.org/10.4236/msa.2013.410077

[23] Sui, J.H. and Cai, W. (2007) Mechanical and Corrosion Study of Diamond-Like Carbon Coating on NiTi Alloys. Surface and Coatings Technology, 201, 5121-5123. http://dx.doi.org/10.1016/j.surfcoat.2006.07.225 
Scientific Research Publishing (SCIRP) is one of the largest Open Access journal publishers. It is currently publishing more than 200 open access, online, peer-reviewed journals covering a wide range of academic disciplines. SCIRP serves the worldwide academic communities and contributes to the progress and application of science with its publication.

Other selected journals from SCIRP are listed as below. Submit your manuscript to us via either submit@scirp.org or Online Submission Portal.
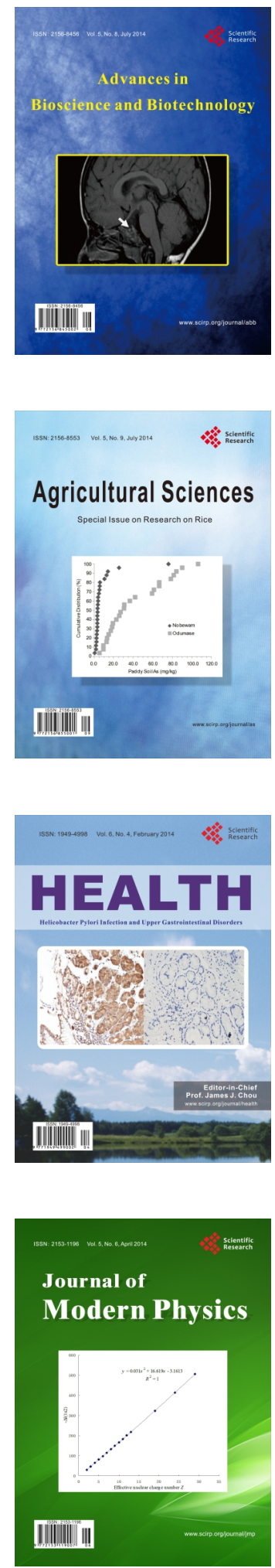
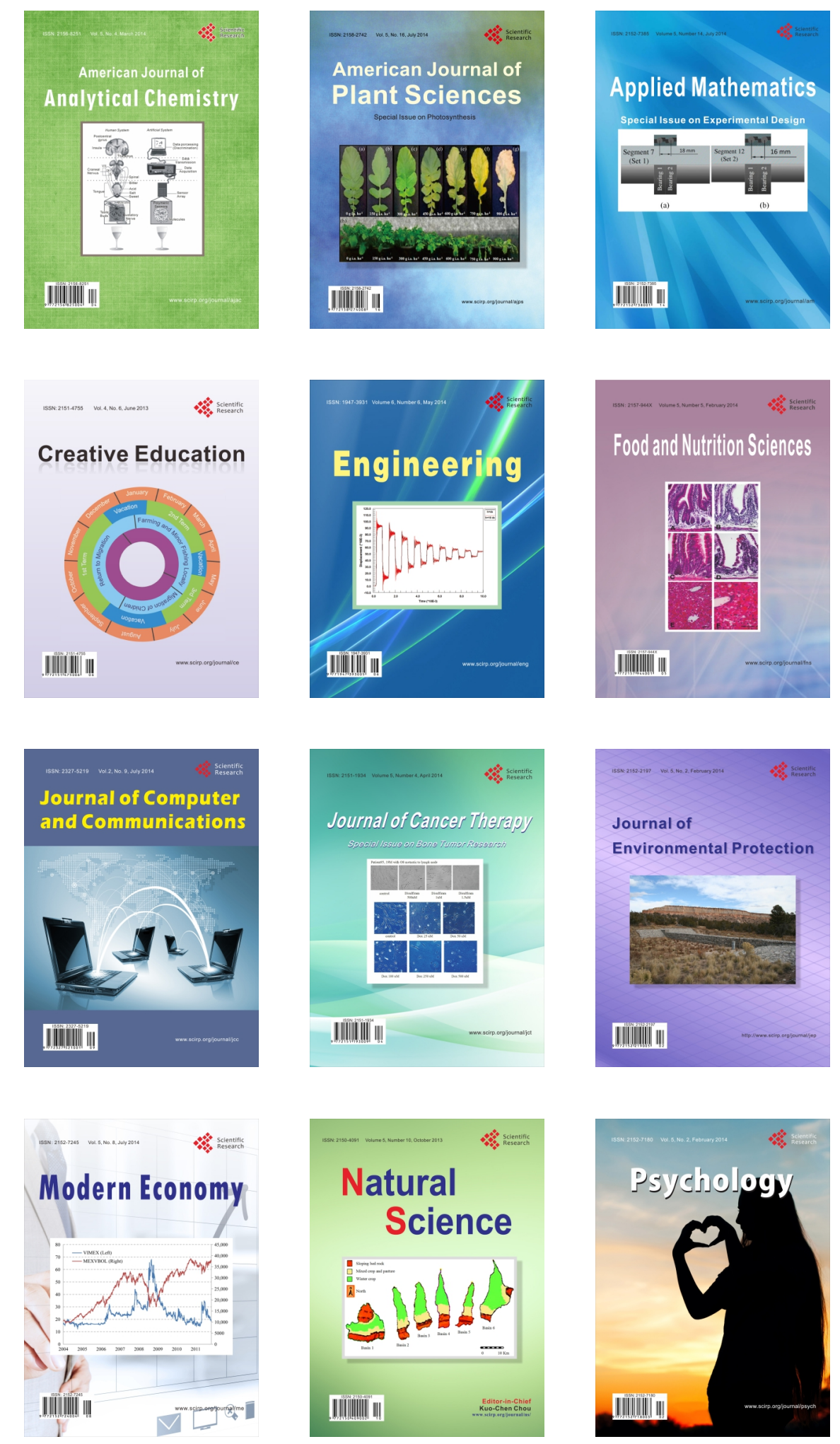